\title{
Canadian Urological Association guideline on the management of non-muscle-invasive bladder cancer - Abridged version
}

\author{
Bimal Bhindi, MD, CM, MSc, FRCSC ${ }^{*}$; Ronald Kool, MD*2; Girish S. Kulkarni, MD, PhD, FRCSC ; \\ D. Robert Siemens, MD, FRCSC, Armen G. Aprikian, MD, FRCSC 2 ; Rodney H. Breau, MD, MSc, FRCSC ; \\ Fadi Brimo, MD, FRCP'; Adrian Fairey, MD, FRCSC ; Christopher French, MD, FRCSC ; \\ Nawar Hanna, MD, MSc, FRCSC ; Jonathan I. Izawa, MD, FRCSC ${ }^{10}$; Louis Lacombe, MD, FRCSC ${ }^{11}$, \\ Victor McPherson, MD, MSc, FRCSC2; Ricardo A. Rendon, MD, FRCSC ${ }^{12}$; Bobby Shayegan, MD, FRCSC ${ }^{13}$; \\ Alan I. So, MD, FRCSC ${ }^{14}$; Alexandre R. Zlotta, MD, PhD, FRCSC ${ }^{15}$; Peter C. Black, MD, FRCSC, FACS ${ }^{14}$; \\ Wassim Kassouf, MD, CM, FRCSC ${ }^{2}$
}

\begin{abstract}
'Section of Urology, Department of Surgery, University of Calgary, Calgary, AB, Canada; ${ }^{2}$ Division of Urology, Department of Surgery, McGill University Health Centre, Montreal, QC, Canada; ${ }^{3}$ Division of Urology, Department of Surgery, Princess Margaret Cancer Centre, University of Toronto, Toronto, ON, Canada; ${ }^{4}$ Department of Urology, Queen's University, Kingston, ON, Canada; ${ }^{5}$ Division of Urology, University of Ottawa, Clinical Epidemiology, The Ottawa Hospital Research Institute, Ottawa, ON, Canada; ${ }^{6}$ Department of Pathology, McGill University Health Centre, Montreal, QC, Canada; ${ }^{7}$ Division of Urology, University of Alberta, Edmonton, AB, Canada; ${ }^{8}$ Division of Urology, Department of Surgery, Memorial University of Newfoundland, St. John's, NL, Canada; ${ }^{9}$ Department of Urology, Université de Montréal, Montreal, QC, Canada; ${ }^{10}$ Department of Surgery, Division of Urology, Western University, London, ON, Canada; "Department of Surgery, Faculty of Medicine, Université Laval, Quebec, QC, Canada; ${ }^{12}$ Department of Urology, Dalhousie University, Halifax, NS, Canada; ${ }^{13}$ Division of Urology, McMaster University, Hamilton, ON, Canada; ${ }^{14}$ Department of Urologic Sciences, University of British Columbia, Vancouver, BC, Canada; ${ }^{15}$ Division of Urology, Department of Surgery, Sinai Health System and Department of Surgical Oncology, University Health Network, Toronto, ON, Canada
\end{abstract}

${ }^{\star}$ Co-first authors with equal contribution

Cite as: Bhindi B, Kool R, Kulkarni GS, et al. Canadian Urological Association guideline on the management of non-muscle-invasive bladder cancer - Abridged version. Can Urol Assoc J 2021;15(8):230-9. http://dx.doi.org/10.5489/cuaj.7487

View full guideline at cuaj.ca and cua.org

\section{Introduction and objectives}

Approximately $75 \%$ of all bladder tumors are diagnosed at early stages and classified as non-muscle-invasive bladder cancer (NMIBC), which corresponds to clinical tumor stages Tis (carcinoma in situ [CIS]), Ta, and T1 according to the eighth edition of the American Joint Committee on Cancer (AJCC) and the International Union Against Cancer (UICC) classification. ${ }^{1}$ For this updated version of the Canadian Urological Association (CUA) guideline on the management of NMIBC, a non-systematic literature review was performed in Medline and PubMed using keywords and MESH terms. Statements were assigned a level of evidence (LE) and recommendations were classified as strong vs. weak (Table 1). ${ }^{2}$ Previously published sections of the 2015 version $^{3}$ were reorganized and updated.

A summary of the main statements and recommendations regarding the management of NMIBC are presented here. A review of the epidemiology and risk factors associated with NMIBC, as well a detailed discussion on the current literature for the topics highlighted in this manuscript are available online (cuaj.ca or cua.org/guidelines).

\section{Risk stratification}

- All patients with NMIBC should be stratified according to the risk of both recurrence and progression for adequate patient counselling and treatment planning ( $L E$ 2, strong recommendation). The modified CUA risk stratification system is a suitable tool for this purpose.

The main risk factors for NMIBC recurrence and progression include pT stage (pTa vs. pT1), grade (high vs. low), presence of concurrent CIS, number of tumors (single vs. multiple), size $(<3 \mathrm{~cm}$ vs. $\geq 3)$, and frequency of previous recurrences ( $\leq 1$ per year vs. $>1$ per year). ${ }^{4-6}$ The modified CUA risk stratification method is proposed here (Table 2). Although further validation is required, this classification can be easily implemented in daily practice. It stratifies patients individually into low-, intermediate- and high-risk NMIBC.

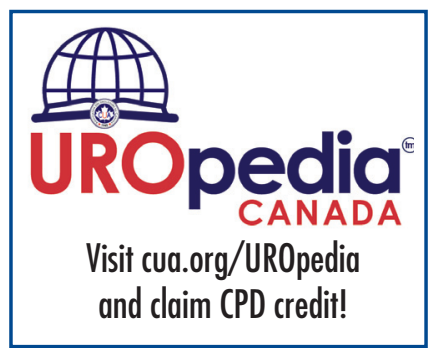




\begin{tabular}{|c|c|c|}
\hline $\begin{array}{l}\text { Level of } \\
\text { evidence }\end{array}$ & Studies on intervention & Studies on prognosis \\
\hline 1 & $\begin{array}{l}\text { Meta-analysis of randomized } \\
\text { controlled trials } \\
\text { Good-quality randomized } \\
\text { controlled trial }\end{array}$ & $\begin{array}{c}\text { Meta-analysis of } \\
\text { inception cohort studies }\end{array}$ \\
\hline 2 & $\begin{array}{l}\text { Low-quality randomized } \\
\text { controlled trial } \\
\text { Good-quality prospective } \\
\text { cohort study }\end{array}$ & Inception cohort study \\
\hline 3 & $\begin{array}{c}\text { Good-quality retrospective } \\
\text { case-control } \\
\text { or cohort study }\end{array}$ & $\begin{array}{l}\text { Cohort study or control } \\
\text { arm of randomized } \\
\text { controlled trial }\end{array}$ \\
\hline 4 & Expert opinion & $\begin{array}{l}\text { Case series, case-control } \\
\text { study, or poor-quality } \\
\text { prognostic cohort study }\end{array}$ \\
\hline
\end{tabular}

\section{Transurethral resection of bladder fumor (TURBT)}

- Initial TURBT aims for complete tumor resection with sampling of the underlying detrusor muscle as the first step of curative-intent treatment of NMIBC (LE 2, strong recommendation). Patients with presumed low grade (LG) Ta or CIS might be spared from muscle sampling at initial TURBT (LE 3, weak recommendation).

- When available, blue light cystoscopy (BLC) (LE 1, weak recommendation) or narrow band imaging (NBI) (LE 2, weak recommendation) can increase tumor detection at first TURBT and reduce recurrence risk.

- A re-staging TURBT should be performed in patients with T1 NMIBC, or when a complete resection was not achieved with the first TURBT (LE 2, strong recommendation). Re-staging TURBT is not required in patients who will proceed to radical cystectomy $(\mathrm{RC})$ based on the findings of the first TURBT.

- In select cases of high-grade (HG) Ta tumors (e.g., large and/or multiple tumors), a re-staging TURBT might be considered (LE 3, weak recommendation).

- The suggested window for a re-staging TURBT is within six weeks of the first resection ( $L E 3$, weak recommendation).

- Patients presenting with a positive urine cytology, but normal-appearing bladder at white light cystoscopy (WLC) and normal upper urinary tract imaging are at higher risk of harboring occult CIS and should undergo random bladder biopsies (or use of BLC with directed biopsies) (LE 2, strong recommendation).

- Biopsies or transurethral resection of the prostatic urethra should be included with random bladder biopsies in the presence of a positive urine cytology, but normal-appearing bladder at WLC and normal upper urinary tract imaging ( $L E 3$, strong recommendation).

- Prostatic urethral biopsy (or transurethral resection) can also be considered in the presence of extensive
Table 2. Modified Canadian Urological Association risk stratification system ${ }^{\dagger}$

\begin{tabular}{|c|c|}
\hline Risk group & Tumor characteristics \\
\hline Low & $\begin{array}{l}\text { 1. PUNLMP } \\
\text { 2. Primary, solitary, and small }(<3 \mathrm{~cm}) \text { LG Ta }\end{array}$ \\
\hline Intermediate & $\begin{array}{l}\text { Patients without CIS who are not included in the } \\
\text { other risk categories: } \\
\text { 1. Recurrent, multifocal, and/or large }(>3 \mathrm{~cm}) \text { LG } \\
\text { Ta } \\
- \text { Consider sub-stratification: } \\
\text { a) Low-intermediate-risk: } 0 \text { factors }{ }^{*}- \\
\text { consider treating as low-risk patients } \\
\text { b) Intermediate-risk: } 1-2 \text { factors } \\
\text { c) High-intermediate-risk: } \geq 3 \text { factors - } \\
\text { consider treating as high-risk patients } \\
\text { * Multiple tumors, }>3 \mathrm{~cm} \text {, time to recurrence } \\
(<1 \text { year), and frequency of recurrence } \\
\text { (>1/year) } \\
\text { 2. Primary, solitary, and small ( }<3 \mathrm{~cm}) \mathrm{HG} \mathrm{Ta} \\
- \text { Consider treating as high-risk patients }\end{array}$ \\
\hline High & 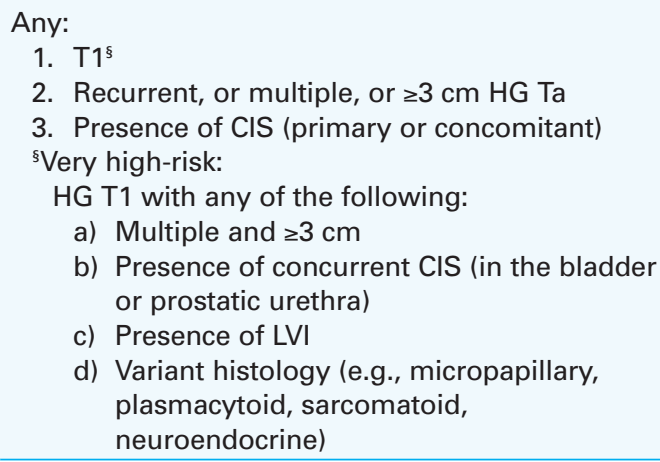 \\
\hline \multicolumn{2}{|c|}{$\begin{array}{l}{ }^{\dagger} \text { Modified from EORTC and CUETO stratification tools, Sylvester et al, }{ }^{6} \text { and other major } \\
\text { guidelines. CIS: carcinoma in situ; HG: high-grade; LG: low-grade; LVI: Iymphovascular } \\
\text { invasion; PUNLMP: papillary urothelial neoplasm of low malignant potential. }\end{array}$} \\
\hline
\end{tabular}

bladder CIS or tumor at the bladder neck or trigone (LE 3, weak recommendation).

- Patients with prostatic urethra involvement (PUI) with CIS restricted to the urethral mucosa can be managed conservatively with transurethral resection of prostate (TURP) plus intravesical bacillus Calmette-Guérin (BCG) (LE 3, weak recommendation). Repeat prostatic urethral biopsies after induction BCG should be considered ( $L E$ 3, weak recommendation). $\mathbf{R C}$ can be discussed as an alternative option ( $L E 4$, weak recommendation).

- In patients with HG T1 or CIS extending into the prostatic ducts, RC should be considered (LE 3, weak recommendation). TURP followed by intravesical BCG is an alternative option. In this instance, close followup with repeat prostatic urethral biopsies after induction BCG should be considered (LE 3, weak recommendation).

- In patients with prostatic stromal invasion, neoadjuvant cisplatin-based chemotherapy followed by RC is recommended (LE 3, strong recommendation; refer to muscle-invasive bladder cancer guideline). 
A high-quality TURBT is of utmost importance for diagnosis, staging, and further management of NMIBC (Table 3). Several clinical trials have evaluated enhanced imaging methods, such as BLC and $\mathrm{NBI}$, with the intent of improving tumor detection rates at cystoscopy/TURBT and reducing disease recurrence. ${ }^{7,8} \mathrm{BLC}$ and $\mathrm{NBI}$ are potential useful tools in the initial management and surveillance of NMIBC. Despite a trend for BLC in decreasing progression rates and prolonging time to progression, current data is inconclusive, and impact on oncological outcomes other than recurrence with either BLC or NBI remains unclear. ${ }^{9}$

A re-staging TURBT within six weeks of the initial procedure aims for identification and resection of residual or previously missed lesions and the identification of occult muscle-invasive disease..$^{10}$ It results in upstaging rates of $0.4 \%(0-8 \%)$ and $8 \%(0-32 \%)$ of initial pTa vs. initial pT1 tumors, respectively, according to a recent systematic review. ${ }^{11}$ In pTa patients, a re-staging TURBT is associated with lower rates of recurrence but not progression, while for $\mathrm{pT} 1$ patients, a re-staging TURBT resulted in lower rates of progression and overall mortality, with additional trend for lower cancer-specific mortality. ${ }^{11}$

The absence of muscularis propria in the first TURBT specimen is a clear indication for a re-staging TURBT in T1 tumors. A similar benefit for Ta tumors, however, is less clear. $^{12,13}$ Therefore, in select cases of HG Ta (e.g., multiple and/or $\geq 3 \mathrm{~cm}$ tumors), a re-staging TURBT might be considered (LE 3, weak recommendation).

The overall detection rate of CIS through random bladder biopsies of normal-appearing mucosa is $17.4 \%$ but

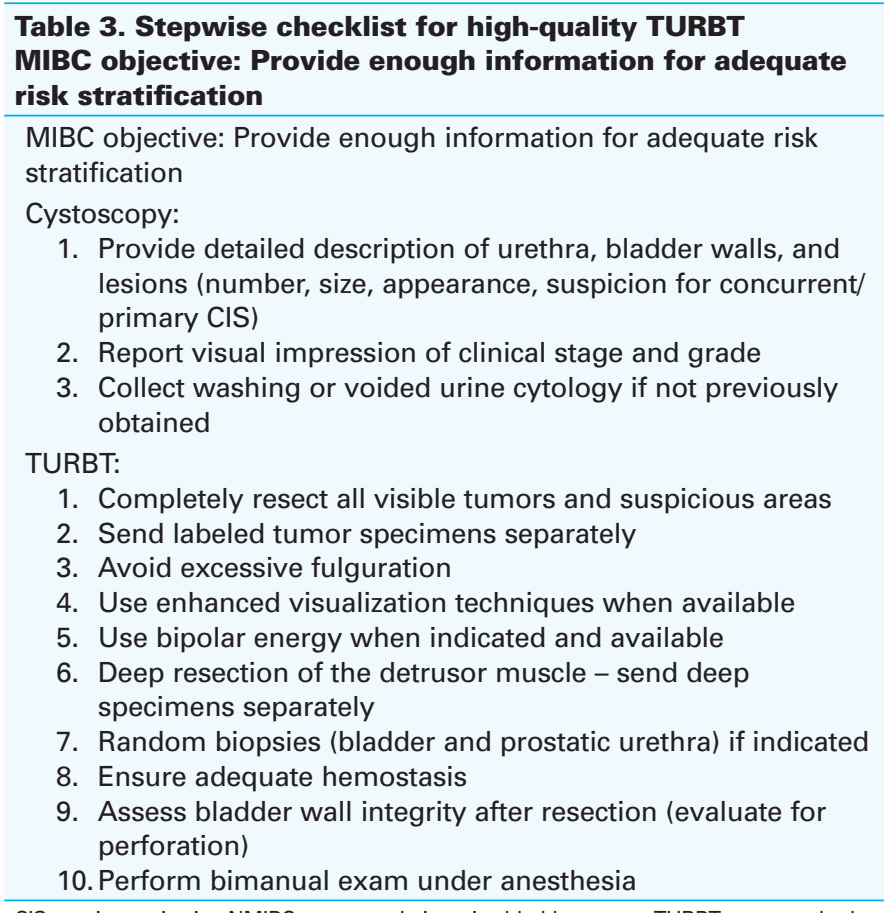

CIS: carcinoma in situ; NMIBC: non-muscle-invasive bladder cancer; TURBT: transurethral resection of bladder tumor. increases to $57.3 \%$ when urine cytology is positive. ${ }^{14}$ In a setting of normal cystoscopy and normal upper urinary tract imaging, random bladder biopsies should be performed if urine cytology is positive ( $L E 2$, strong recommendation). In this scenario, enhanced imaging methods may play a role in identifying targets for directed biopsy when cystoscopy is normal, also aiming for higher detection of CIS in those cases (LE 3, strong recommendation). ${ }^{15}$

Incidence of primary prostatic urethral urothelial carcinoma is rare $(1-4 \%)$, but contiguous PUI by bladder cancer can range from $12-48 \%$ according to retrospective series (LE 3). ${ }^{16,17}$ A clear association between CIS detected in the prostatic urethra and worse oncological outcomes has been demonstrated. ${ }^{18,19}$ Prostatic urethral biopsies can be considered in patients with tumors located at the bladder neck and trigone, those with associated bladder CIS, and whenever bladder urine cytology is positive in the setting of a negative cystoscopy and normal upper tract imaging (LE 3, weak recommendation). ${ }^{20}$

Moreover, the depth of invasion of PUI is associated with oncological outcomes. ${ }^{21}$ Patients with PUI limited to the mucosa have better prognosis and can be managed with TURP, followed by intravesical BCG. ${ }^{22,23}$ On the other hand, $\mathrm{RC}$ should be considered in patients with ductal invasion ( $L E$ 3, weak recommendation), although bladder preservation with TURP followed by BCG has been described in small retrospective series. ${ }^{24}$ Finally, invasion of the prostatic stroma requires aggressive treatment with neoadjuvant chemotherapy followed by $\mathrm{RC} \pm$ urethrectomy (refer to muscle-invasive bladder cancer guideline). ${ }^{23}$

\section{Intravesical therapy}

First-line adjuvant intravesical therapy options consist mainly of chemotherapy and immunotherapy (including BCG). It is administered with therapeutic (treatment of CIS or residual non-visible tumor) and prophylactic (prevention of recurrence and progression of disease) intents.

\subsection{Single instillation of chemotherapy (SIC) post-TURBT}

- $\quad$ SIC (with mitomycin C [MMC], epirubicin, doxorubicin, pirarubicin, or gemcitabine) should be offered to all patients with presumed low-risk NMIBC at TURBT and administered within 24 hours after endoscopic resection ( $L E$ 1, strong recommendation).

- SIC is recommended for intermediate-risk NMIBC and patients with $\leq 1$ recurrence/year and European Organisation for Research and Treatment of Cancer (EORTC) recurrence score $<\mathbf{5}$ (LE 1, strong recommendation). SIC should be discussed even when further adjuvant intravesical chemotherapy is planned ( $L E 2$, weak recommendation). 
- The benefit of SIC in patients with high-risk NMIBC is unclear when BCG is planned as adjuvant treatment (LE 3).

- SIC should not be administered after extensive resection or when bladder perforation is suspected ( $L E 3$, strong recommendation).

SIC was initially proposed with the intent of reducing the number of floating malignant cells in the bladder after a TURBT, preventing cancer cell re-implantation, and reducing early recurrence rates after resection. In addition, this approach might have an ablative effect on small occult tumors and is recommended in patients with presumed lowrisk NMIBC. ${ }^{25}$

In 2004, Sylvester et al published a meta-analysis including 1476 patients, mostly low-risk, where one immediate instillation of chemotherapy with either MMC, epirubicin, or pirarubicin after TURBT was associated with a 39\% decrease in the odds of recurrence favoring SIC (LE 1, strong recommendation). The benefit, however, was not statistically significant for patients with multiple tumors when adjusted for stage. ${ }^{26}$ The most recent meta-analysis revisiting the topic in 2016 was published again by Sylvester et al, this time including individual data analysis of 2278 randomized patients. ${ }^{27}$ A reduction of $35 \%$ in the relative risk of recurrence was reported favoring SIC (hazard ratio [HR] 0.65, $\mathrm{p}<0.001$ ), with five-year recurrence of $44.8 \%$ vs. $58.8 \%$ for TURBT alone (LE 1). This study showed no benefit of SIC for patients with more than one recurrence per year and those with an EORTC recurrence score $\geq 5 .{ }^{27}$

A large, multicenter trial by Bosschieter et al randomized 2243 patients to receive intravesical instillation of MMC within the first 24 hours after TURBT (immediate) or two weeks after the procedure (delayed). ${ }^{28}$ Recurrence rates at three years were $27 \%$ in the immediate vs. $36 \%$ in the delayed instillation group $(p<0.001)$, reflecting a $34 \%$ reduction in the relative risk favoring immediate instillation ( $L E$ 1). Despite possible selection bias and unique risk stratification (LG T1 tumors were classified as low-risk; multiple tumors as high-risk), this was the first study suggesting lower rates of recurrence even in patients with intermediate- and high-risk disease who received further adjuvant intravesical instillations. ${ }^{28}$ Furthermore, in a re-analysis of this same trial using updated risk definition, the authors concluded that the benefit of SIC was significant regardless of risk group and suggested that SIC should not be withheld from intermediate- and high-risk patients. ${ }^{29}$

For intermediate- and high-risk patients, current data is conflicting regarding the benefit of SIC post-TURBT. Patients who fall into the high-risk category but meet the criteria of EORTC score for recurrence $<5$ (http://www.eortc.be/tools/ bladdercalculator/) may be considered for SIC (LE 3, weak recommendation). The benefit of SIC for high-risk patients with multiple and large tumors who are planned for further BCG treatment is unclear, as patients from the study by Bosschieter et al treated with adjuvant therapy received intravesical chemotherapy rather than BCG (LE 3). ${ }^{30-32}$

\subsection{Adjuvant intravesical chemotherapy}

- Patients with intermediate-risk NMIBC should be considered for adjuvant induction intravesical chemotherapy ( $L E 1$, strong recommendation) with subsequent monthly maintenance for up to one year ( $L E 3$, weak recommendation), or induction BCG with maintenance therapy (refer to section 3.3).

- Sub-stratification of intermediate-risk patients with recurrent LG Ta NMIBC can be used to guide adjuvant treatment decisions ( $L E 3$, weak recommendation). For this purpose, four factors should be considered: number of tumors, size $(\geq 3 \mathrm{~cm})$, time to recurrence $(<1$ year), and frequency of recurrence ( $>1$ /year).

$\circ$ Patients with low-intermediate-risk NMIBC (0 factors) may be treated similarly to low-risk patients, with SIC alone (LE 3, weak recommendation).

- Patients with high-intermediate-risk NMIBC $(\geq 3$ factors) may be treated as high-risk patients with induction and maintenance BCG (LE 3, weak recommendation).

- Patients who develop recurrence during intravesical chemotherapy may be offered induction followed by maintenance BCG (LE 3, weak recommendation).

No further treatment is needed other than SIC following tumor resection for low-risk patients, while intermediate- and high-risk patients should be considered for additional intravesical therapy. Several randomized controlled trials (RCTs) have shown lower rates of recurrence for patients undergoing induction intravesical chemotherapy with or without maintenance therapy, using either MMC, epirubicin, doxorubicin, or pirarubicin, compared to TUR alone (LE 1). ${ }^{33-36}$

Although RCTs comparing induction only vs. induction intravesical chemotherapy followed by maintenance have shown conflicting results, this approach might be considered monthly for up to one year for intermediate- and high-risk patients in which an initial response to induction therapy was achieved after TURBT (LE 3, weak recommendation). 34,35,37-42

In 2010, a sub-stratification of intermediate-risk patients with recurrent LG Ta disease was proposed considering four factors: number of tumors (multiplicity), tumor size $(>3 \mathrm{~cm}$ ), early recurrence ( $<1$ year), and recurrence frequency $(>1$ per year). ${ }^{43}$ As presented in Table 2, patients with none of the factors are classified as having "low-intermediate-risk" disease and can be managed similarly to low-risk patients with SIC. Those with 1-2 factors are considered true "intermediate-risk" patients and should be managed with adjuvant intravesical 
chemotherapy (induction followed by one-year maintenance) or BCG (induction followed by that maintenance for one year with three weekly instillations at three, six, and 12 months). Finally, patients with $\geq 3$ factors are the "high-intermediate-risk" group and should be treated as high-risk patients, with full BCG schedule (induction followed by maintenance for three years with three weekly instillations at three, six, 12, 18, 24, 30, and 36 months). ${ }^{44}$ Similarly, intermediate-risk patients with primary, small, and solitary HG Ta should be treated as high-risk patients with induction BCG followed by maintenance therapy.

\section{3. $B C G$}

- In patients with high-risk NMIBC, BCG therapy with weekly induction (for six weeks) followed by three-year maintenance (weekly instillations for three weeks at three, six, 12, 18, 24, 30, and 36 months) is the standard for reducing disease recurrence and progression rates ( $L E 1$, strong recommendation).

- When BCG is administered for intermediate-risk NMIBC, induction followed by one-year maintenance is recommended ( $L E 1$, strong recommendation).

\subsubsection{Oncological outcomes and BCG}

BCG has been the standard of care for decreasing not only recurrence, but also progression rates for high-risk NMIBC (LE 1, strong recommendation). ${ }^{45-50} \mathrm{~A}$ meta-analysis including 4863 patients from 24 RCTs showed that $9.8 \%$ of patients progressed in the BCG group vs. $13.8 \%$ in controls, reflecting a $27 \%$ relative reduction in the odds of progression (odds ratio [OR] 0.73, $\mathrm{p}=0.001$ ) in favor of $\mathrm{BCG} .{ }^{46}$ Notably, the benefit of BCG over other intravesical regimens was seen only in patients treated with BCG maintenance, rather than induction only (LE 1). ${ }^{46}$

For concurrent or primary CIS, BCG is the standard of care, as it eradicates CIS and reduces risk of both recurrence and progression. The meta-analysis by Sylvester et al in 2002 highlighted that the benefit of BCG in progression was seen for both papillary tumors and CIS. ${ }^{46}$ In 2005, another metaanalysis compared patients with CIS treated with intravesical chemotherapy $(\mathrm{MMC}$, epirubicin, doxorubicin, or sequential MMC/doxorubicin) vs. BCG. ${ }^{50}$ They found that treatment failure and progression rates were higher with intravesical chemotherapy regimens compared with BCG (LE 1). ${ }^{50}$

Although BCG is associated with more adverse effects than intravesical chemotherapy, serious toxicity occurs in only $5 \%$ of patients. ${ }^{46,51}$ The most common local side effect of BCG instillation is the development of cystitis-like symptoms (urgency, dysuria, and increased urinary frequency) that can be present in up to $71 \%$ of patients. ${ }^{52}$ The management of BCG-related adverse effects is presented in Table 4.

\begin{tabular}{|c|c|}
\hline & Management \\
\hline \multicolumn{2}{|l|}{$\begin{array}{l}\text { Local side } \\
\text { effects }\end{array}$} \\
\hline $\begin{array}{l}\text { Visible } \\
\text { hematuria }\end{array}$ & $\begin{array}{l}\text { Suspend BCG until resolved; laboratory workup } \\
\text { (urine, blood, cultures); culture-directed antibiotics } \\
\text { for UTI, if present; if hematuria is persistent, then } \\
\text { perform cystoscopy to rule out bladder cancer } \\
\text { recurrence }\end{array}$ \\
\hline $\begin{array}{l}\text { Epididymitis/ } \\
\text { prostatitis }\end{array}$ & $\begin{array}{c}\text { Suspend BCG; laboratory workup (urine, blood, } \\
\text { cultures); add antibiotics (e.g., quinolones); } \\
\text { consider INZ } 300 \text { mg/day or RFP } 600 \text { mg/day; } \\
\text { consider infectious disease consultation; } \\
\text { consider orchiectomy }\end{array}$ \\
\hline \multicolumn{2}{|l|}{$\begin{array}{l}\text { Systemic } \\
\text { side effects }\end{array}$} \\
\hline $\begin{array}{l}\text { Malaise/ } \\
\text { nausea } \\
\text { (usually } \\
<48 \text { h) }\end{array}$ & Symptomatic treatment (e.g., antiemetics) \\
\hline $\begin{array}{l}\text { Allergic } \\
\text { reactions }\end{array}$ & $\begin{array}{l}\text { Mild and <48h: Antihistamines; NSAID - delay } \\
\text { BCG until resolved } \\
\text { Persistent: Suspend BCG and consider discontinue } \\
\text { treatment; consider INZ } 300 \mathrm{mg} / \text { day or RFP } \\
\quad 600 \mathrm{mg} / \text { day }\end{array}$ \\
\hline Fever & $\begin{array}{c}<38.5^{\circ} \mathrm{C} \text { and/or }<48 \mathrm{~h} \text { : Symptomatic treatment } \\
\text { (e.g., antipyretics) } \\
\geq 38.5^{\circ} \mathrm{C} \text { for } \geq 48 \mathrm{~h} \text { : Suspend BCG until resolved/ } \\
\text { consider dose reduction; laboratory workup (urine, } \\
\text { blood, cultures); start with at least } 2 \text { empiric } \\
\text { antimicrobials (e.g., quinolones, INZ } 300 \mathrm{mg} / \mathrm{day} \text {, } \\
\text { RFP } 600 \mathrm{mg} / \text { day); consider infectious disease } \\
\text { consultation }\end{array}$ \\
\hline BCG sepsis & $\begin{array}{l}\text { Suspend BCG definitively; hospitalization; } \\
\text { laboratory workup (urine, blood, cultures); start } \\
\text { empiric antibiotics (e.g., high-dose quinolones); } \\
\text { initiate INZ } 300 \mathrm{mg} / \text { day + RFP } 600 \mathrm{mg} / \text { day + } \\
\text { ethambutol } 1200 \mathrm{mg} / \text { day, for } 6 \text { months); high-dose } \\
\text { corticosteroids if persistent (e.g., prednisolone } \\
\quad 40 \mathrm{mg} / \text { day); infectious disease consult }\end{array}$ \\
\hline
\end{tabular}

\subsection{2. $B C G$ failure}

In order to standardize BCG failure and increase homogeneity among patients who are unlikely to respond to further intravesical BCG therapy, the term "BCG-unresponsive" NMIBC was developed by a consensus panel representing experts from the American Urological Association and the US Food and Drug Administration (FDA) (www.fda.gov/ media/101468/download). Current BCG failure classification is presented in Table 5.

\subsubsection{Management of BCG-unresponsive NMIBC}

- $\quad$ RC with pelvic lymph node dissection is the standard of care for BCG-unresponsive bladder cancer in surgically fit patients ( $L E 3$, strong recommendation). For patients 
with BCG-unresponsive CIS or HG Ta, a second-line intravesical therapy might be considered before RC ( $L E$ 3 , weak recommendation).

- Promising efficacy has been reported with intravenous pembrolizumab, intravesical oportuzumab monatox, nadofaragene firadenovec, and BCG plus $\mathrm{N}-803$. These should be considered as potential options in patients with BCG-unresponsive CIS who are unfit for or refuse to undergo $\mathbf{R C}$ ( $L E 2$, weak recommendation).

- Alternative options, such as sequential intravesical gemcitabine/docetaxel (induction plus maintenance), may be considered for patients with BCG-unresponsive disease who are unfit for or refuse to undergo $\mathbf{R C}$ ( $L E$ 3 , weak recommendation). Additional alternatives may also include other combination intravesical therapy (e.g., sequential gemcitabine/MMC, BCG + interferon if available) or single-agent intravesical therapy (MMC, epirubicin, docetaxel, gemcitabine) (LE 3, weak recommendation).

- Clinical trials may still be considered for BCGunresponsive patients who are unfit for or refuse to undergo RC.

$\mathrm{RC}$ is the standard for patients with BCG-unresponsive NMIBC, and studies have shown that patients with recurrent disease benefit from early radical surgery ( $L E 3$, strong recommendation). ${ }^{53}$ Patients considered surgically unfit and those unwilling to undergo RC should be counselled regarding higher risks of recurrence and progression associated with bladder preservation. Whenever available, enrolment in a clinical trial should also be considered (LE 3, weak recommendation).

\begin{tabular}{|c|c|}
\hline $\begin{array}{l}\text { BCG failure } \\
\text { stratification }\end{array}$ & Definition $^{\dagger}$ \\
\hline BCG-unresponsive & $\begin{array}{l}\text { HG T1 at the first evaluation following } \\
\text { induction BCG (3 months) } \\
\text { Recurrent HG Ta/T1 within } 6 \text { months of } \\
\text { adequate BCG treatment* } \\
\text { Recurrent CIS within } 12 \text { months of last } \\
\text { adequate BCG treatment* }\end{array}$ \\
\hline BCG refractory & $\begin{array}{l}\text { HG T1 at the first evaluation following } \\
\text { induction BCG ( } 3 \text { months) } \\
\text { Persistent/recurrent } \mathrm{HG} \mathrm{Ta/CIS} \mathrm{following} \\
\text { adequate BCG (6 months)* }\end{array}$ \\
\hline BCG relapsing & $\begin{array}{l}\text { HG recurrence after reaching a disease-free } \\
\text { state within } 6 \text { months of receiving adequate } \\
\qquad \text { BCG* }^{*}\end{array}$ \\
\hline BCG intolerant & $\begin{array}{c}\text { Disease recurrence/persistence after failure } \\
\text { to receive adequate BCG therapy due to } \\
\text { severe adverse effects }\end{array}$ \\
\hline \multicolumn{2}{|c|}{$\begin{array}{l}\text { 'By definition, low-grade recurrences during or after BCG are not considered BCG } \\
\text { failure. *Adequate BCG - at least 5-6 weekly induction courses followed by at least one } \\
\text { maintenance cycle (consisting of at least } 2 \text { out of } 3 \text { weekly BCG treatments) or a second } \\
\text { induction cycle (whereby at least } 2 \text { of } 6 \text { weekly instillations were received). BCG: bacillus } \\
\text { Calmete-Guérin; CIS: carcinoma in situ; HG: high-grade. }\end{array}$} \\
\hline
\end{tabular}

Single-agent therapies demonstrated only modest efficacy for BCG-unresponsive disease. ${ }^{54-58}$ Therefore, patients undergoing intravesical chemotherapy might be considered for sequential combination of drugs, such gemcitabine followed by MMC or gemcitabine followed by docetaxel (LE 3, weak recommendation). ${ }^{59,60}$ Novel agents, such as pembrolizumab, nadofaragene firadenovec, oportuzumab monatox, and BCG $+\mathrm{N}-803$ were tested in patients with BCG-unresponsive CIS with promising results. ${ }^{61-64}$ Complete response rates at three months reported in these trials ranged from $40.0-53.4 \%(71 \%$ at any time for BCG $+\mathrm{N}-803)$, with durable response rates at 12 years of $45.5-56.0 \%$. A summary of the management of NMIBC is presented in Fig. 1.

\subsubsection{Treatment adjustments only if BCG shortage}

- For patients with intermediate-risk NMIBC during BCG shortage, intravesical chemotherapy is recommended as the first-line option. If BCG is planned as a second-line therapy for this population, it might be administered with reduced dose (1/2 or $1 / 3$ dose) and maintenance can be omitted (LE 3, weak recommendation).

- For patients with high-risk NMIBC, full BCG schedule is recommended ( $L E 1$, strong recommendation). Only during BCG shortage, when full dose is not possible due to limited supply, dose reduction to $1 / 2$ or $1 / 3$ might be considered, while maintenance can be reduced to one year ( $L E 3$, weak recommendation).

- When BCG is unavailable, single-agent chemotherapy (e.g., MMC, gemcitabine) or sequential combination of intravesical chemotherapy (e.g., gemcitabine/ docetaxel) is recommended with induction followed by monthly maintenance for up to one year ( $L E 3$, weak recommendation).

The worldwide BCG shortage remains a challenge and urologists should be aware that alternatives in this scenario are continuously being studied and discussed by the scientific community. Moreover, in June 2019, the medical advisory board of Bladder Cancer Canada, together with the CUA Guidelines Committee, released a document in response to continuous limited supply of the Tice strain of BCG in Canada (https://bladdercancercanada.org/wp-content/uploads/2019/06/Approach-to-Address-BCG-Shortageupdated-June-2019.pdf).

\section{Timely cystectomy}

- Upfront RC should be considered for patients with large-volume, diffuse, endoscopically unresectable NMIBC (LE 3, strong recommendation).

- Upfront RC should be offered to patients with HGT1 disease with additional adverse tumor pathological features: variant histology (e.g., micropapillary, plasmacytoid, sar- 


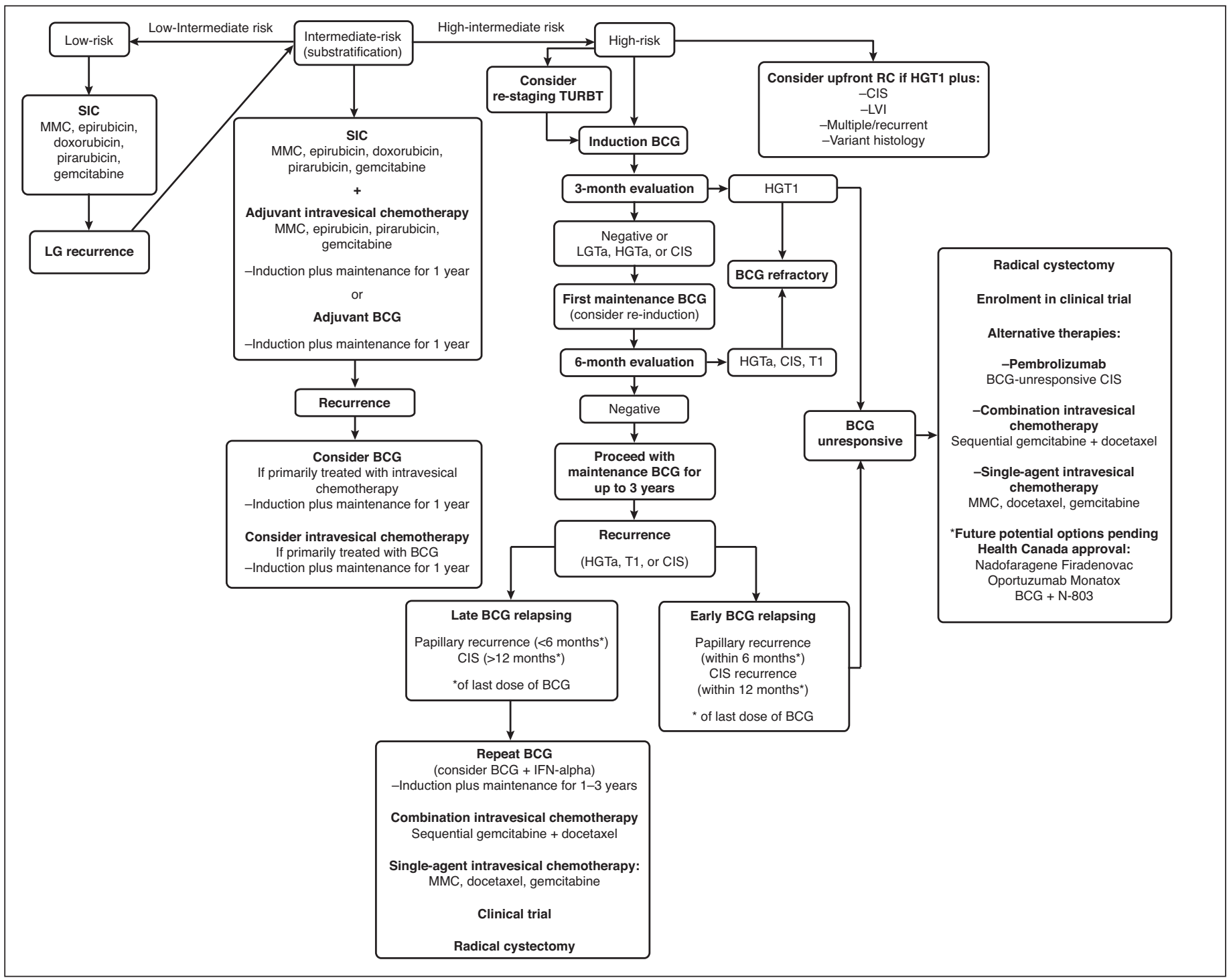

Fig. 1. Flow chart. * Modified from Chehroudi et al. ${ }^{79} \mathrm{BCG}$ : bacillus de Calmette-Guérin; CIS: carcinoma in situ; GEM: gemcitabine; HG: high-grade; Ind: induction; LG: low-grade; LVI: Iymphovascular invasion; MMC: mitomycin-C; RC: radical cystectomy; SIC: single instillation of chemotherapy; TURBT: transurethral resection of bladder tumor.

comatoid), extensive invasion of the lamina propria or invasion into or beyond the muscularis mucosa $(\mathrm{T} 1 \mathrm{~b} / \mathrm{c})$, presence of lymphovascular invasion (LVI), concomitant CIS in the bladder or prostatic urethra, multiple and large $(\geq 3 \mathrm{~cm})$ tumors, or persistent HG T1 upon re-staging TURBT (LE 3, strong recommendation).

Timely RC is an important consideration for patients with NMIBC considered at higher risk of progression. ${ }^{53,65}$ For HG recurrent NMIBC despite adequate BCG therapy, any further attempt at bladder preservation is not ideal and early RC should be offered whenever feasible (strong recommendation). Furthermore, patients with de novo high-risk disease and additional high-risk features discussed in this guideline should also be offered timely RC ( LE 3, strong recommenda- tion), particularly those with variant histology (micropapillary, plasmacytoid, and sarcomatoid) or the following risk factors: extensive or deep T1 invasion, multiple/large tumors, CIS (bladder and/or prostate), LVI, persistent T1 disease at re-staging TURBT, tumor found at initial three-month cystoscopy, and pT1 recurrence (LE 4). ${ }^{66}$

\section{Followup}

- The first surveillance cystoscopy is recommended for all patients at three months after TURBT (LE 2, strong recommendation).

- After the three-month cystoscopy, a risk-based surveillance strategy should be used in patients with no evidence of recurrence: 


\begin{tabular}{|c|c|}
\hline $\begin{array}{l}\text { Risk } \\
\text { stratification }\end{array}$ & Surveillance schedule \\
\hline $\begin{array}{l}\text { Low-risk } \\
\text { NMIBC }\end{array}$ & $\begin{array}{l}\text { - } \text { Assessment with cystoscopy at } 3 \text { months } \\
\text { - } \text { Cystoscopy at } 1 \text { year, then yearly until } 5 \text { years } \\
\text { - } \text { Consider fulguration under local anesthesia } \\
\text { for small ( }<5 \mathrm{~mm} \text { ), LG Ta tumors with } \\
\text { negative cytology }\end{array}$ \\
\hline $\begin{array}{l}\text { Intermediate- } \\
\text { risk NMIBC }\end{array}$ & $\begin{array}{l}\text { - Assessment with cystoscopy and urine } \\
\text { cytology at } 3 \text { months } \\
\text { - Cystoscopy + urine cytology every 3-6 } \\
\text { months for } 2 \text { years, every } 6-12 \text { months until } \\
\text { 4th year and yearly thereafter }\end{array}$ \\
\hline $\begin{array}{l}\text { High-risk } \\
\text { patients }\end{array}$ & $\begin{array}{l}\text { - Assessment with cystoscopy and urine } \\
\text { cytology at } 3 \text { months } \\
\text { - Cystoscopy + urine cytology every } 3-4 \\
\text { months for } 2 \text { years, every } 6 \text { months until 5th } \\
\text { year and yearly thereafter } \\
\text { - Upper tract evaluation within } 12 \text { months, then } \\
\text { every } 2 \text { years thereafter }\end{array}$ \\
\hline $\begin{array}{l}\text { Modified and adapt } \\
\text { bladder cancer. }\end{array}$ & from Kassouf et al.78 LG: low-grade; NMIBC: non-muscle-invasive \\
\hline
\end{tabular}

○ Low-risk patients might be followed with cystoscopy at one year and then yearly for five years ( $L E$ 3, weak recommendation). Urinary cytology is not necessary in the followup of low-risk patients ( $L E$ 4, weak recommendation).

- Intermediate-risk patients should be followed with cystoscopies and urine cytology every 3-6 months in the first two years, every 6-12 months in the third year, and annually thereafter (LE 3, weak recommendation).

○ High-risk patients should be followed with cystoscopies and urine cytology every 3-4 months during the first two years, every six months during years 3 and 4, and annually thereafter (LE 3, weak recommendation).

- Upper tract imaging is recommended with random bladder/prostatic urethral biopsies (or use of BLC with directed biopsies) if positive urine cytology with normal cystoscopy is found during surveillance (LE 3, weak recommendation).

- Upper tract imaging surveillance is recommended in the first year and every two years thereafter for highrisk patients ( $L E 3$, weak recommendation).

- Fulguration under local anesthesia might be considered for small $(<5 \mathrm{~mm})$ papillary tumors and negative cytology in patients with a prior history of papillary urothelial neoplasm of low malignant potential (PUNLMP) or LG Ta tumors (LE 3, weak recommendation).

There is currently no high-level evidence on specific surveillance protocols for the different stages of NMIBC. Due to high rates of recurrences for low-risk and progression for high-risk patients, surveillance for NMIBC should be diligent and ideal followup consists of adapting strategies based on individual risk ( $L E$ 3). ${ }^{4,5}$ General recommendations are that all newly diagnosed patients treated with initial TURBT should undergo a first assessment at three months with voided urine cytology (except low-risk NMIBC) and cystoscopy. Cystoscopic and pathological findings at first three-month assessment post-TURBT are associated with oncological outcomes (recurrence and progression), particularly for high-risk patients. ${ }^{4,67,68}$ Additionally, urine cytology is a useful tool during surveillance for high-risk patients, with sensitivity as high as $70-90 \% .{ }^{69-72} \mathrm{~A}$ risk-stratified schedule for NMIBC followup is presented in Table 6.

Competing interests: Dr. Bhindi has been an advisory board member for Bayer and Janssen; and has received speaker honoraria from Merck. Dr. Kulkarni has been an advisory board member for Astellas, Ferring, Janssen, Merck, Roche, and Theralase; has received grants and/or honoraria from Abbvie, Ferring, Sanofi, and TerSera; and has participated in clinical trials supported by Merck, Astra Zeneca, Bristol Myers Squibb, Janssen, and Theralase. Dr. Siemens has participated in clinical trials supported by Astellas, Merck, and Pfizer. Dr. Aprikian has been an advisory board member for Abbvie, Astellas, and Bayer; and has received grants and/or honoraria from Abbvie, Astellas, Bayer, Sanofi, and TerSera. Dr. Hanna has received honoraria from Astellas and Bayer; and has participated in clinical trials supported by Merck. Dr. Izawa has received honoraria from Abbvie. Dr. McPherson has been an advisory board member for Abbvie and TerSera; has received travel funding from TerSera; and has participated in clinical trials supported by Bristol-Myers Squibb and Pfizer. Dr. Rendon has been an advisory board member for Abbvie, Amgen, Astellas, AstraZeneca, Bayer, Ferring, Janssen, Pfizer, Roche, and Sanofi; a speakers' bureau member for Abbvie, Amgen, Astellas, AstraZeneca, Bayer, Ferring, Janssen, Pfizer, Roche, and Sanofi; has received grants and/or honoraria from Abbvie, Astellas, Bayer, Ferring, Janssen, and Sanofi; holds investments in Myovant; and has participated in clinical trials supported by Abbvie, Astellas, Bayer, Bavarian Nordic, Ferring, Janssen, Myovant, and Sanofi. Dr. Shayegan has been an advisory board member for AbbVie, Astellas, Bayer, Ferring Janssen, Knight, Merck, Pfizer, Sanofi, and TerSera; and has participated in clinical trials supported by Ipsen, Janssen, Merck, Myovant, and Pfizer. Dr. So has been an advisory board member for Abbvie, Amgen, Astellas, Bayer, Janssen, Ferring, and TerSera; and has participated in clinical trials supported by Astellas, Ferring, and Janssen. Dr. Zlotta has been an advisory board member for AstraZeneca, Ferring, Janssen, Merck, Sanofi, and Verity. Dr. Black has been an advisory board member for AbbVie, Asieris, Astellas, AstraZeneca, Bayer, Biosyent, BMS, EMD-Serono, Ferring, Fergene, H3-Biomedicine, Janssen, Merck, Protara Therapeutics, Roche, Sanofi, and Urogen; a speakers' bureau member for AbbVie, Biosyent, Ferring, Janssen, Pfizer, and TerSera; has received payment from Bayer and Sanofi; has received grants and/or honoraria from iProgen; holds a patent marketed by Decipher Biosciences; and has participated in clinical trials supported by Astellas, AstraZeneca, BMS, Genentech, Janssen, MDx Health, Pacific Edge, and Therelase. Dr. Kassouf has been an advisory board member for EMD Serono and Pfizer; has received grants and/or honoraria from Abbvie, Astellas, BMS, Ferring, Janssen, Merck, Roche, and Sesen Bio; and has participated in clinical trials supported by Astra Zeneca, BMS, Janssen, Pfizer, Roche, Sesen Bio, and Theralase. No other authors report any competing personal or financial interests related to this work.

\section{References}

1. Amin M, Edge S, Greene F, et al. AJCC Cancer Staging Manual, Springer. 2017. https://doi. org/10.1007/978-3-319-40618-3_2

2. Guyatt GH, Oxman AD, Vist GE, et al. GRADE: An emerging consensus on rating quality of evidence and strength of recommendations. BMJ 2008;336:924-6. https://doi.org/10.1136/bmi.39489.470347. $\mathrm{AD}$

3. Kassouf W, Traboulsi SL, Kulkarni GS, et al. CUA guidelines on the management of non-muscle invasive bladder cancer. Can Urol Assoc J 2015;9:E690-704. https://doi.org/10.5489/cuaj.3320 
4. Sylvester RJ, van der Meiiden APM, Oosterlinck W, et al. Predicting recurrence and progression in individuol patients with stage Ta TI bladder cancer using EORTC risk tables: A combined analysis of 2596 patients from seven EORTC trials. Eur Urol 2006;49:466-77. https://doi.org/10.1016/i.eururo.2005.12.031

5. Fernandez-Gomez J, Madero R, Solsona E, et al. Predicting non-muscle-invasive bladder cancer recurrence and progression in patients treated with bacillus Calmette-Guérin: The CUETO scoring model. J Urol 2009;182:2195-203. https://doi.org/10.1016/i.juro.2009.07.016

6. Sylvester RJ, Rodríguez 0, Hernández V, et al. European Association of Urology (EAU) prognostic factor risk groups for non-muscle-invasive bladder cancer (NMIBC) incorporating the WHO 2004/2016 and WHO 1973 classification systems for grade: An update from the EAU NMIBC guidelines panel. Eur Urol 2021;79:480-8. https://doi.org/10.1016/i.eururo.2020.12.033

7. Burger $M$, Grossman $H B$, Droller $M$, et al. Photodynamic diagnosis of non-muscle-invasive bladder cancer with hexaminolevulinate cystoscopy: A meta-analysis of detection and recurrence based on raw data. Eur Urol 2013;64:846-54. https://doi.org/10.1016/i.eururo.2013.03.059

8. Naito S, Algaba F, Babjuk M, et al. The Clinical Research Office of the Endourological Society (CROES) multicenter, randomized trial of narrow band imaging-assisted transurethral resection of bladder tumor (TURBT) vs. conventional white light imaging-assisted TURBT in primary non-muscle-invasive bladder cancer patients: Trial protocol and 1-year results. Eur Urol 2016;70:506-15. https://doi.org/10.1016/i. eururo.2016.03.053

9. Gakis $G$, Fahmy 0 . Systematic review and meta-analysis on the impact of hexaminolevulinate- vs. whitelight-guided transurethral bladder tumor resection on progression in non-muscle-nnvasive bladder cancer. Bladder Cancer 2016;2:293-300. https://doi.org/10.3233/BLC-160060

10. Brausi M, Collette L, Kurth K, et al. Variability in the recurrence rate at first followup cystoscopy after TUR in stage Ta $\mathrm{Tl}$ transitional cell carcinoma of the bladder: A combined analysis of seven EORTC studies. Eur Urol 2002;41:523-31. htrps://doi.org/10.1016/50302-2838(02)00068-4

11. Cumberbatch MGK, Foerster B, Catto JWF, et al. Repeat transurethral resection in non-muscle-invasive bladder cancer: A systematic review. Eur Urol 2018;73:925-33. https://doi.org/10.1016/i.eururo.2018.02.014

12. Taoka R, Matsuoka Y, Kohashiguchi K, et al. Impact of second transurethral resection on recurrence in patients with high-grade Ta bladder cancer. Int J Urol 2020;27:1130-5. https://doi.org/10.1111/ iju. 14372

13. Mastroianni R, Brassetti A, Krajewski W, et al. Assessing the impact of the absence of detrusor muscle in Ta low-grade urothelial carcinoma of the bladder on recurrence-free survival. Eur Urol Focus 2020 Sep 6;S2405-4569(20)30220-0. https://doi.org/10.1016/i.euf.2020.08.007

14. Subiela JD, Palou J, Esquinas C, et al. Clinical usefulness of random biopsies in diagnosis and treatment of non-muscle invasive bladder cancer: Systematic review and meta-analysis. Actas Urol Esp 2018;42:28598. https://doi.org/10.1016/i.acuro.2017.10.001

15. Wities JA, Babjuk M, Gontero P, et al. Clinical and cost effectiveness of hexaminolevulinate-guided bluelight cystoscopy: Evidence review and updated expert recommendations. Eur Urol 2014;66:863-71. https://doi.org/10.1016/i.eururo.2014.06.037

16. Lerner SP, Shen S. Pathologic assessment and clinical significance of prostatic involvement by transitional cell carcinoma and prostate cancer. Urol Oncol 2008;26:481-5. https://doi.org/10.1016/i. urolonc.2008.03.002

17. Walsh DL, Chang SS. Dilemmas in the treatment of urothelial cancers of the prostate. Urol Oncol 2009;27:352-7. https://doi.org/10.1016/i.urolonc.2007.12.010

18. Grabstald H. Prostatic biopsy in selected patients with carcinoma in situ of the bladder: Preliminary report. J Urol 1984;132:1117-8. hrtps://doi.org/10.1016/50022-5347(17)50055-5

19. Bretton PR, Herr HW, Whitmore WF, et al. Intravesical bacillus Calmette-Guérin therapy for in situ transitional cell carcinoma involving the prostatic urethra. J Urol 1989;141:853-5. https://doi.org/10.1016/ S0022-5347(17)41031-7

20. Sakamoto $\mathrm{N}$, Tsuneyoshi $M$, Naito $\mathrm{S}$, et al. An adequate sampling of the prostate to identify prostatic involvement by urothelial carcinoma in bladder cancer patients. J Urol 1993;149:318-21. https://doi.org/10.1016/S0022-5347(17)36068-8

21. Solsona E, Iborra I, Ricos JV, et al. The prostate involvement as prognostic factor in patients with superficial bladder tumors. J Urol 1995; 154:1710-3. https://doi.org/10.1016/50022-5347(01)66762-4

22. Palou J, Sylvester RJ, Faba OR, et al. Female gender and carcinoma in situ in the prostatic urethra are prognostic factors for recurrence, progression, and disease-specific mortality in TIG3 bladder cancer patients treated with bacillus Calmette-Guérin. Eur Urol 2012;62:118-25. https://doi.org/10.1016/i eururo.2011.10.029

23. Palou J, Baniel J, Klotz L, et al. Urothelial carcinoma of the prostate. Urology 2007;69:50-61. https://doi.org/10.1016/i.urology.2006.05.059

24. Palou Redorta J, Schatteman P, Huguet Pérez J, et al. Intravesical instillations with bacillus Calmette-Guérin for the treatment of carcinoma in situ involving prostatic ducts. Eur Urol 2006;49:834-8; discussion 8. https://doi.org/10.1016/i.eururo.2005.12.019

25. Pan IS, Slocum HK, Rustum YM, et al. Inhibition of implantation of murine bladder tumor by thiotepa in cauterized bladder. J Urol 1989;142:1589-93. https://doi.org/10.1016/S0022-5347(17)39174-7
26. Sylvester RJ, Oosterlinck W, van der Meiiden AP. A single, immediate postoperative instillation of chemotherapy decreases the risk of recurrence in patients with stage Ta TI bladder cancer: A meta-analysis of published results of randomized clinical trials. J Urol 2004;171:2186-90, quiz 435. https://doi. org/10.1097/01.ju.0000125486.92260.b2

27. Sylvester RJ, Oosterlinck W, Holmang S, et al. Systematic review and individual patient data meta-analysis of randomized trials comparing a single, immediate instillation of chemotherapy after transurethral resection with transurethral resection alone in patients with stage pTa-pTl urothelial carcinoma of the bladder: Which patients benefit from the instillation? Eur Urol 2016;69:231-44. https://doi.org/10.1016/i. eururo.2015.07.018

28. Bosschieter J, Nieuwenhuijzen JA, van Ginkel $\mathrm{T}$, et al. Value of an immediate intravesical instillation of mitomycin C in patients with non-muscle-invasive bladder cancer: A prospective multicenter, randomized study in 2243 patients. Eur Urol 2018;73:226-32. https://doi.org/10.1016/i.eururo.2017.06.038

29. Bosschieter J, Nieuwenhuïzen JA, Vis AN, et al. An immediate, single intravesical instillation of mitomycin $C$ is of benefit in patients with non-muscle-invasive bladder cancer irrespective of prognostic risk groups. Urol Oncol 2018;36:400.e7-14. https://doi.org/10.1016/i.urolonc.2018.05.026

30. Oosterlinck $W$, Decaestecker $K$. An immediate intravesical instillation of mitomycin $C$ is of benefit in all prognostic risk groups with non-muscle-invasive bladder cancers. Transl Androl Urol 2018;7:S706-9. https://doi.org/10.21037/tau.2018.10.07

31. Bosschieter J, van Moorselaar RJA, Nieuwenhuïzen JA. An immediate, single instillation of mitomycin C in non-muscle invasive bladder cancer: Can we define which patients do and do not benefit? Trans/ Androl Urol 2019:S346-S7. https://doi.org/10.21037/tau.2019.03.08

32. Elsawy AA, El-Assmy AM, Bazeed MA, et al. The value of immediate postoperative intravesical epirubicin instillation as an adjunct to standard adjuvant treatment in intermediate and high-risk non-muscle-invasive bladder cancer: A preliminary results of randomized controlled trial. Urol Oncol 2019;37:179.e9-18. https://doi.org/10.1016/i.urolonc.2018.10.019

33. Koga $H$, Kuroiwa K, Yamaguchi A, et al. A randomized controlled trial of short-term vs. long-term prophylactic intravesical instillation chemotherapy for recurrence after transurethral resection of $\mathrm{Ta} / \mathrm{Tl}$ transitional cell carcinoma of the bladder. J Urol 2004;171:153-7. https://doi.org/10.1097/01. ju. $0000100386.07370 .0 a$

34. Friedrich MG, Pichlmeier U, Schwaibold $H$, et al. Long-term intravesical adjuvant chemotherapy further reduces recurrence rate compared with short-term intravesical chemotherapy and short-term therapy with bacillus Calmette-Guérin (BCG) in patients with non-muscle-nnvasive bladder carcinoma. Eur Urol 2007;52:1123-9. htrps://doi.org/10.1016/i.eururo.2007.02.063

35. Matsumura Y, Akaza H, Isaka S, et al. The 4th study of prophylactic intravesical chemotherapy with adriamycin in the treatment of superficial bladder cancer: The experience of the Japanese Urological Cancer Research Group for Adriamycin. Cancer Chemother Pharmacol 1992;30Suppl:S10-4. https://doi.org/10.1007/BF00686934

36. Naya Y, Mikami K, Takaha N, et al. Randomized study of intravesical pirarubicin chemotherapy with low and intermediate-risk non-muscle-invasive bladder cancer in Japan: Comparison of a single immediate postoperative intravesical instillation with short-term adjuvant intravesical instillations after transurethral resection. Medicine (Baltimore) 2018;97:e12740. https://doi.org/10.1097/MD.0000000000012740

37. Koga H, Kuroiwa K, Yamaguchi A, et al. A randomized controlled trial of short-term vs. long-term prophylactic intravesical instillation chemotherapy for recurrence after transurethral resection of Ta/Tl transitional cell carcinoma of the bladder. J Urol 2004;171:153-7. https://doi.org/10.1097/01. ju.0000100386.07370.0a

38. Okamura K, Kinukawa T, Tsumura Y, et al. A randomized study of short- vs. long-term intravesical epirubicin instillation for superficial bladder cancer. Nagoya University Urological Oncology Group. Eur Urol 1998;33:285-8; discussion 9. https://doi.org/10.1159/000019581

39. Tolley DA, Parmar MK, Grigor KM, et al. The effect of intravesical mitomycin C on recurrence of newly diagnosed superficial bladder cancer: A further report with 7 years of followup. J Urol 1996; 155:1233-8. https://doi.org/10.1016/S0022-5347(01)66226-8

40. Medical Research Council Working Party on Urological Cancer, Subgroup on Superficial Bladder Cancer. The effect of intravesical thiotepa on tumor recurrence after endoscopic treatment of newly diagnosed superficial bladder cancer. A further report with long-term followup of a Research Council randomized trial. Medical Br J Urol 1994;73:632-8. https://doi.org/10.1111/i.1464-410X.1994.tb07547.x

41. Huncharek M, Geschwind JF, Witherspoon B, et al. Intravesical chemotherapy prophylaxis in primary superficial bladder cancer: A meta-analysis of 3703 patients from 11 randomized trials. J Clin Epidemiol 2000;53:676-80. https://doi.org/10.1016/S0895-4356(99)00203-6

42. Tabayoyong WB, Kamat AM, $O^{\prime}$ Donnell MA, et al. Systematic review on the utilization of maintenance intravesical chemotherapy in the management of non-muscle-invasive bladder cancer. Eur Urol Focus 2018;4:512-21. hrtps://doi.org/10.1016/i.euf.2018.08.019

43. Lamm D, Persad $R$, Colombel $M$, et al. Maintenance bacillus Calmette-Guérin: The standard of care for the prophylaxis and management of intermediate- and high-risk non-muscle-invasive bladder cancer. Eur Urol Suppl 2010;9:715-34. https://doi.org/10.1016/i.eursup.2010.08.005 
44. Peyton CC, Chipollini J, Azizi M, et al. Updates on the use of intravesical therapies for non-muscle invasive bladder cancer: How, when, and what. World I Urol 2019;37:2017-29. https://doi.org/10.1007/ s00345-018-2591-1

45. Huncharek M, Kupelnick B. Impact of intravesical chemotherapy vs. BCG immunotherapy on recurrence of superficial transitional cell carcinoma of the bladder: Meta-analytic re-evaluation. Am J Clin Oncol 2003;26:402-7. https://doi.org/10.1097/01.COC.0000026911.98171.C6

46. Sylvester RJ, van der MA, Lamm DL. Intravesical bacillus Calmette-Guerin reduces the risk of progression in patients with superficial bladder cancer: A meta-analysis of the published results of randomized clinical trials. J Urol 2002;168:1964-70. https://doi.org/10.1016/S0022-5347(05)64273-5

47. Bohle A, Jocham D, Bock PR. Intravesical bacillus Calmette-Guérin vs. mitomycin C for superficial bladder cancer: A formal meta-analysis of comparative studies on recurrence and toxicity. J Urol 2003;169:90-5. https://doi.org/10.1016/S0022-5347(05)64043-8

48. Bohle A, Bock PR. Intravesical bacille Calmette-Guérin vs. mitomycin C in superficial bladder cancer: Formal meta-analysis of comparative studies on tumor progression. Urology 2004;63:682-6; discussion 6-7. https://doi.org/10.1016/i.urology.2003.11.049

49. Shelley MD, Wilt TJ, Court J, et al. Intravesical bacillus Calmette-Guérin is superior to mitomycin C in reducing tumour recurrence in high-risk superficial bladder cancer: A meta-analysis of randomized trials. BJU Int 2004;93:485-90. https://doi.org/10.1111/i.1464-410X.2003.04655.x

50. Sylvester RJ, van der Meijden APM, Witjes JA, et al. Bacillus Calmette-Guérin vs. chemotherapy for the intravesical treatment of patients with carcinoma in situ of the bladder: A meta-analysis of the published results of randomized clinical trials. J Urol 2005;174:86-92. https://doi.org/10.1097/01. ju.0000162059.64886.1c

51. van der Meiiden APM, Sylvester RJ, Oosterlinck W, et al. Maintenance bacillus Calmette-Guérin for Ta Tl bladder tumors is not associated with increased toxicity: Results from a European Organisation for Research and Treatment of Cancer Genito-Urinary Group phase 3 trial. Eur Urol 2003;44:429-34. https://doi.org/10.1016/S0302-2838(03)00357-9

52. Schmidt $S$, Kunath F, Coles B, et al. Intravesical bacillus Calmette-Guérin vs. mitomycin C for Ta and TI bladder cancer. Cochrane Database Syst Rev 2020;1:Cd01 1935. https://doi.org/10.1002/14651858. CD011935.pub2

53. Herr HW, Sogani PC. Does early cystectomy improve the survival of patients with high-risk superficia bladder tumors? J Urol 2001;166:1296-9. https://doi.org/10.1016/S0022-5347(05)65756-4

54. Dinney $\mathrm{CP}$, Greenberg RE, Steinberg GD. Intravesical valrubicin in patients with bladder carcinoma in situ and contraindication to or failure after bacillus Calmette-Guérin. Urol Oncol 2013;31:1635-42. hitps://doi.org/10.1016/i.urolonc.2012.04.010

55. Laudano MA, Barlow L, Murphy AM, et al. Long-term clinical outcomes of a phase 1 trial of intravesical docetaxel in the management of non-muscle-invasive bladder cancer refractory to standard intravesical therapy. Urology 2010;75:134-7. https://doi.org/10.1016/i.urology.2009.06.112

56. Morales A, Herr H, Steinberg G, et al. Efficacy and safety of MCNA in patients with non-muscle-invasive bladder cancer at high risk for recurrence and progression after failed treatment with bacillus CalmetteGuérin. J Urol 2015;193:1135-43. https://doi.org/10.1016/i.juro.2014.09.109

57. McKiernan JM, Holder DD, Ghandour RA, et al. Phase 2 trial of intravesical nanoparticle albumin bound paclitaxel for the treatment of non-muscle invasive urothelial carcinoma of the bladder after bacillus Calmette-Guérin treatment failure. J Urol 2014;192:1633-8. https://doi.org/10.1016/i. juro.2014.06.084

58. Skinner EC, Goldman B, Sakr WA, et al. SWOG S0353: Phase 2 trial of intravesical gemcitabine in patients with non-muscle-invasive bladder cancer and recurrence after 2 prior courses of intravesical bacillus Calmette-Guérin. J Urol 2013;190:1200-4. https://doi.org/10.1016/i.uuro.2013.04.031

59. Lightfoot AJ, Brever BN, Rosevear HM, et al. Multi-institutional analysis of sequential intravesical gemcitabine and mitomycin C chemotherapy for non-muscle invasive bladder cancer. Urol Oncol 2014;32:35. e15-9. https://doi.org/10.1016/i.urolonc.2013.01.009

60. Steinberg RL, Thomas U, Brooks N, et al. Multi-institution evaluation of sequential gemcitabine and docetaxel as rescue therapy for non-muscle-invasive bladder cancer. J Urol 2020;203:902-9. https://doi.org/10.1097/JU.0000000000000688

61. Balar AV, Kamat AM, Kulkarni GS, et al, Pembrolizumab monotherapy for the treatment of high-risk non-muscle-invasive bladder cancer unresponsive to BCG (KEYNOTE-057): An open-label, single-arm, multicenter, phase 2 study. Lancet Oncol 2021;22:919-30. https://doi.org/10.1016/S1470$2045(21) 00147-9$
62. Boorijan $S A$, Alemozaffar $M$, Konety BR, et al. Intravesical nadofaragene firadenovec gene therapy for BCG-unresponsive non-muscle-invasive bladder cancer: A single-arm, open-label, repeat-dose clinical trial. Lancet Oncol 2021;22:107-17. https://doi.org/10.1016/i.eururo.2021.01.027

63. Dickstein R, Wu N, Cowan B, et al. LBA27 phase 3 study of vicinium in BCG-unresponsive nonmuscle-invasive bladder cancer: Initial results. J Urol 2018;199:e1167. https://doi.org/10.1016/i. juro.2018.03.099

64. Chamie K, Lee JH, Rock A, et al. Preliminary phase 2 clinical results of IL-15R Fc superagonist N-803 with BCG in BCG-unresponsive non-muscle-invasive bladder cancer (NMIBC) patients. J Clin Oncol 2019:37:4561. https://doi.org/10.1200/JC0.2019.37.15 suppl.4561

65. Jäger $W$, Thomas $C$, Haag S, et al. Early vs. delayed radical cystectomy for 'high-risk' carcinoma not invading bladder muscle: Delay of cystectomy reduces cancer-specific survival. BJU Int 201 1;108:E284-8. https://doi.org/10.1111/j.1464-410X.2010.09980.x

66. Klaassen Z, Kamat AM, Kassouf W, et al. Treatment strategy for newly diagnosed TI high-grade bladder urothelial carcinoma: New insights and updated recommendations. Eur Urol 2018;74:597-608. htrps://doi.org/10.1016/i.eururo.2018.06.024

67. Millan-Rodriguez F, Chechile-Toniolo G, Salvador-Bayari J, et al. Multivariate analysis of the prognostic factors of primary superficial bladder cancer. J Urol 2000;163:73-8. https://doi.org/10.1016/S0022$5347(05) 67975-X$

68. Solsona E, Iborra I, Dumont R, et al. The 3-month clinical response to intravesical therapy as a predictive factor for progression in patients with high-risk superficial bladder cancer. J Urol 2000;164:685-9. https://doi.org/10.1016/S0022-5347(05)67281-3

69. Ramakumar S, Bhuiyan J, Besse JA, et al. Comparison of screening methods in the detection of bladder cancer. J Urol 1999;161:388-94. https://doi.org/10.1016/S0022-5347(01)61899-8

70. Brown FM. Urine cytology. It is still the gold standard for screening? Urol Clin North Am 2000;27:25-37. https://doi.org/10.1016/S0094-0143(05)70231-7

71. Raitanen M-P, Aine R, Rintala E, et al. Differences between local and review urinary cytology in diagnosis of bladder cancer. An interobserver multicenter analysis. Eur Urol 2002;41:284-9. https://doi. org/10.1016/S0302-2838(02)00006-4

72. Yafi FA, Brimo F, Steinberg J, et al. Prospective analysis of sensitivity and specificity of urinary cytology and other urinary biomarkers for bladder cancer. Urol Oncol 2015;33:66.e25-31. https://doi. org/10.1016/i.urolonc.2014.06.008

73. Griffin JG, Holzbeierlein J. Side effects of perioperative intravesical treatment and treatment strategies for these side effects. Urol Clin North Am 2013;40:197-210. https://doi.org/10.1016/i.ucl.2013.01.005

74. Rischmann P, Desgrandchamps F, Malavaud B, et al. BCG intravesical instillations: Recommendations for side-effects management. Eur Urol 2000;37Suppl 1:33-6. https://doi.org/10.1159/000052381

75. Koya MP, Simon MA, Soloway MS. Complications of intravesical therapy for urothelial cancer of the bladder. J Urol 2006; 175:2004-10. https://doi.org/10.1016/S0022-5347(06)00264-3

76. Mathes J, Todenhofer T. Managing toxicity of intravesical therapy. Eur Urol Focus 2018;4:464-7. https:// doi.org/10.1016/i.euf.2018.09.009

77. Witjes JA, Palou J, Soloway M, et al. Clinical practice recommendations for the prevention and management of intravesical therapy-associated adverse events. Eur Urol Suppl 2008;7:667-74. https://doi. org/10.1016/i.eursup.2008.08.001

78. Kassouf W, Traboulsi SL, Schmitz-Drager B, et al. Followup in non-muscle-invasive bladder cancerInternational Bladder Cancer Network recommendations. Urol Oncol 2016;34:460-8. https://doi. org/10.1016/i.urolonc.2016.05.028

79. Chehroudi AC, Black PC. Emerging intravesical therapies for the management of bacillus Calmette-Guérin (BCG)-unresponsive non-muscle-invasive bladder cancer: Charting a path forward. Can Urol Assoc J 2020;14:204-13. https://doi.org/10.5489/cuaj.6101

Correspondence: Dr. Wassim Kassouf, Department of Urology, McGill University Health Centre, Montreal, QC, Canada; wassim.kassouf@muhc.mcgill.ca 